\title{
A MINI REVIEW: OPTIMAL DYE REMOVAL BY FENTON PROCESS CATALYSED WITH WASTE MATERIALS
}

\author{
Aleksandra Kulić Mandić ${ }^{1}$ (D), Milena Bečelić-Tomin ${ }^{1}$ (D), Đurđa Kerkez ${ }^{1}$ (D), \\ Gordana Pucar Milidrag ${ }^{1}$ (D), Vesna Pešić ${ }^{1}$ (D), Miljana Prica ${ }^{2}$ (i) \\ ${ }^{1}$ University of Novi Sad, Faculty of Sciences, Department of Chemistry, Biochemistry and \\ Environmental Protection, Novi Sad, Serbia \\ ${ }^{2}$ University of Novi Sad, Faculty of Technical Sciences, Department of Graphic Engineering and \\ Design, Novi Sad, Serbia
}

\begin{abstract}
Large quantities of solid waste from different industries are commonly disposed in landfills, where can generate wide range of environmental problems. Therefore, the aim of this paper is to give insight on the usage of various waste materials as oxidation catalysts in different Fenton processes for dye removal. In that manner the circular value chain of these materials will be reinforced, obtaining disposal cost reduction and further value addition. Some of industrial wastes (fly ash, electric arc furnace dust, red mud, coal bottom ash, activated carbon from biomass, etc.) that have been used to catalyse Fenton reaction in various researches are reviewed from optimization point of view. Both types of optimization, one-factor-at-a-time (OFAT) and response surface methodology (RSM) are investigated. The study revealed that factors as catalyst concentration, $\mathrm{pH}$ value, hydrogen peroxide concentration, dye concentration and reaction time are main factors that influence final Fenton capacity as oxidation process catalysed with reviewed waste materials.
\end{abstract}

Key words: Waste, Catalyst, Dye, Optimization, Fenton

\section{INTRODUCTION}

One of high demanding industries in terms of water and chemical usage is the textile industry. Only in wet process of cotton dying more than $100 \mathrm{~L}$ of water is spent per $\mathrm{kg}$ of textile. Also, unfixed dyes are a known problem in textile effluents, whose chemical structures widely differentiate (Kerkez et al, 2018; Kulić et al, 2018; Nasuha et al, 2017). Wastewater treatment is necessary to obtain an acceptable effluent quality for its discharge in the environment and thus contribute to industrial sustainability.

Worldwide legislation is forcing industries to treat wastewater to the level without any negative influence on the environment and aquatic organisms. Among biological and physicochemical treatments, Fenton process stands out between advanced oxidation processes as efficient in dye degradation (Rubeena et al, 2018; Becelic-Tomin et al, 2014). That does not exclude its use in the treatment of other toxic organic pollutants. The heterogeneous Fenton process is based on $\mathrm{H}_{2} \mathrm{O}_{2}$ reaction with $\mathrm{Fe}$ (or other transition metals) ions present on the catalyst surface, thus producing highly reactive species - hydroxyl radicals $(\bullet \mathrm{OH})$. Pollutants oxidation takes place through a chemical reaction with $\bullet \mathrm{OH}$ in an aqueous solution and on the catalyst surface, where chemisorption of $\bullet \mathbf{O H}$ and pollutants is possible (Drumm et al, 2019). Simplified heterogeneous Fenton reaction mechanism and the main environmental problem of the textile industry are illustrated in Figure 1. In order to mineralize dye molecules (inorganic degradation intermediates, $\mathrm{H}_{2} \mathrm{O}$ and $\mathrm{CO}_{2}$ ) optimization if often needed. Literature research points out to a few efficiency determining factors, such as $\mathrm{pH}$ value, initial oxidant concentration, catalyst concentration, dye concentration, reaction time and temperature (Grassi et al, 2020; Drumm et al, 2019). Their influence is commonly investigated through one-factor-at-a-time (OFAT) and response surface methodology (RSM). Differences between them will be further explained in the Methods section.

The number of materials used as a heterogeneous Fenton catalyst is high, and two main types are supported and non-supported materials. Different solids can be used as a support for active ions and generally those are: clays, zeolites, silica, activated carbon and biosorbents (Maleki Rizi et al, 2019; Zhou et al, 2015). Physicochemical treatment is often required for the dispersion of active ions on the support surface. While non-supported ones already have Fe and/or other transition metal species present on the surface. They can be used without any treatment, but also chemical and/or physical treatments may be implemented in order to improve overall catalyst activity. Typical examples are: red mud, pyrite ash/cinder, fly ash, blast furnace dust, electric arc furnace dust, coal bottom ash (Drumm et al, 2019; Nasuha et al, 2017; Becelic-Tomin et al, 2014). 
The main focus of this study is on solid wastes that can be used beneficially in a heterogeneous Fenton treatment of coloured wastewaters. Such application is an alternative to landfill disposal and promotes industrial symbiosis. Also, cost reduction of handling solid waste is reinforced and further value addition is boosted.

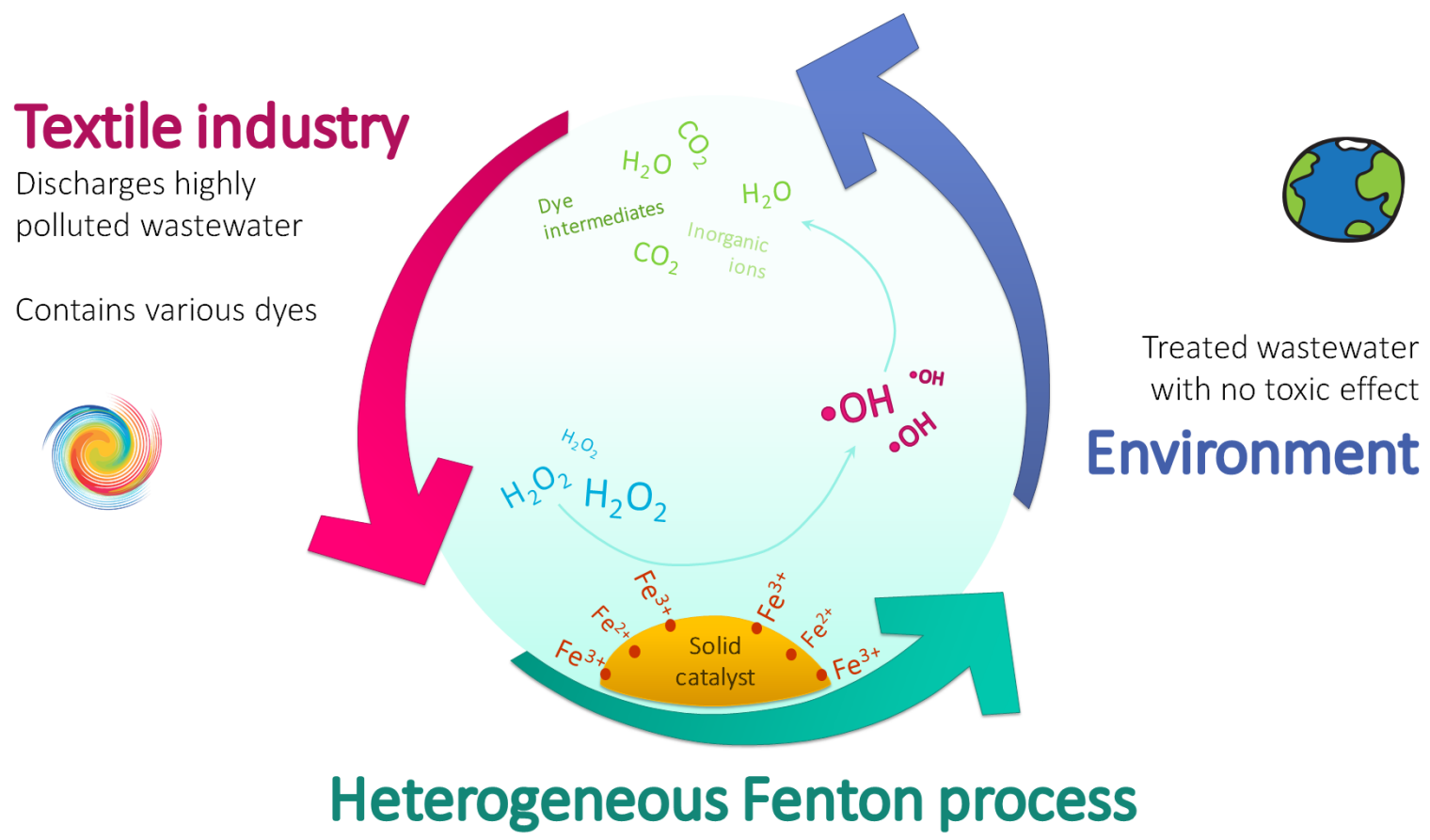

Figure 1: Illustrative depiction of textile industry main environmental problem and heterogeneous Fenton process mechanism for degradation of present dyes

\section{METHODS}

Optimization studies are based on screening experiments in order to determine which factors have the greatest (positive or negative) impact on Fenton process outcome (decolourization efficiency). The commonly used approach is OFAT, where one parameter influence is explored while all other significant process variables are kept constant (Karimifard and Moghaddam, 2018). This type of univariate analysis may suggest inadequate optimal conditions due to the narrow experimental domain.

Statistical design of experiments, on which RSM is based, has been recognized in recent years by researchers since interaction effects between parameters is easier to study and determine (Karimifard and Moghaddam, 2018). Some of the main advantages of using a multivariate approach are: (1) process is optimized with lesser number of experiment probes than in OFAT method, (2) understanding the wide experimental range of tested process parameters, (3) comparing and analysing factor interactions and nonlinear relationships with the response and (4) obtained data quality can be confirmed by statistical analysis. Thus, experiments are performed with less time, cost and physical consumption (Drumm et al, 2019; de Matos Vargas et al, 2019). Central composite design (CCD) and Box-Behnken (BBD) are widely used multi-factor optimization techniques, based on the fit of empirical models to the experimentally obtained data. A CCD has three groups of design points: (1) two-level factorial, (2) central points which present replicate terms, and they are used for estimation of experimental error and (3) axial or star points who are fixed axially and are used as quadratic terms (Grassi et al, 2020). A BBD has fewer points than CCD because star points are not included in this design. Both designs are used for fitting second order polynomial equations, by which it is possible to determine optimal Fenton reaction conditions (Karimifard and Moghaddam, 2018). Design Expert, Minitab and Statistica are commonly used softwares for data processing. Figure 2. presents visual differences in explored design space with OFAT and RSM methodology. 


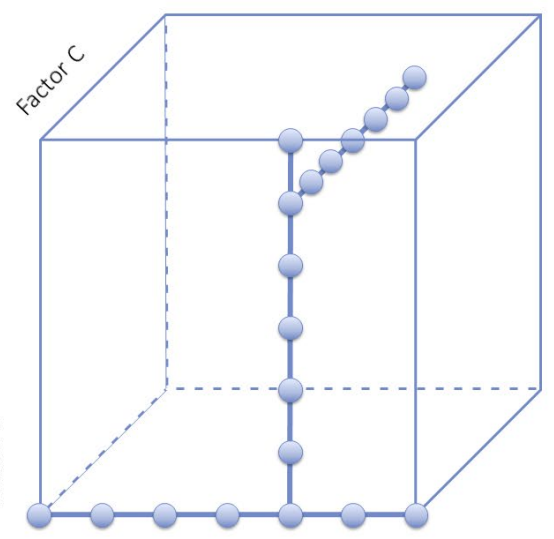

Factor A

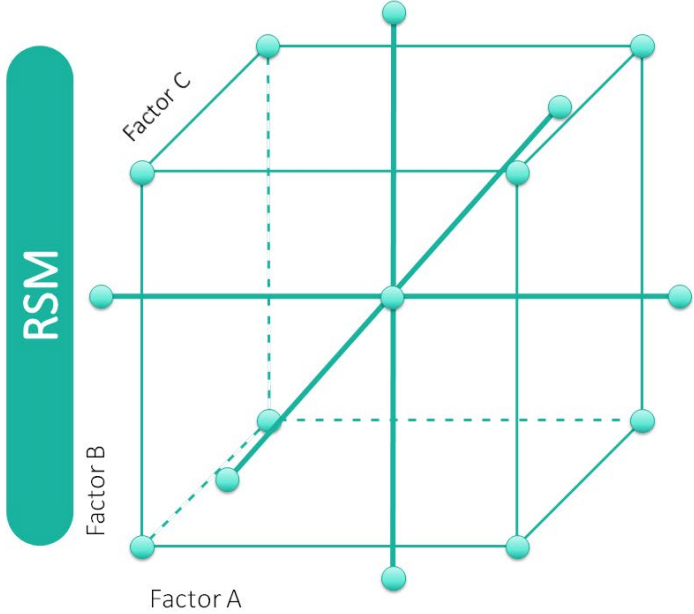

Factor A

Figure 2: Experiment design space explored by OFAT and RSM (CCD) approach

\section{RESULTS AND DISCUSSION}

The waste management focus is to control and decrease waste and non-wanted by-products generation, and also their recycling. General practices are waste collecting and sorting, if possible, materials are recovered. End-of-life practices imply waste reduction, thermal and biological processes and materials recycling techniques (Taelman et al, 2018; Natarajan and Ponnaiah, 2017; Rajput et al, 2016). In this paper, we will focus on possible waste recycling in textile wastewater treatment, thus supporting industrial symbiosis and environmental sustainability.

Firstly, researches based on OFAT methodology will be evaluated. Figure 3. presents results of selected papers of the heterogeneous Fenton process with foundry sand (Fe and steel metal casting), steel industry waste (Fe dust and furnace slag), fly ash (coal burning furnace), pyrite ash and cinder (pyrite roasting furnace), which were used without further modification. These wastes were applied for aqueous dye solutions and real textile effluent treatment. Rajput et al (2016) have investigated the removal of reactive, diazo dye $(100 \mathrm{mg} / \mathrm{L})$ in photo-Fenton process, catalysed with foundry sand and fly ash. Low initial $\mathrm{H}_{2} \mathrm{O}_{2}$ concentration and fly ash concentration were needed to significantly degrade dye molecules in short time. When comparing it with foundry sand (higher catalyst concentration and longer reaction period were required), fly ash showed great potential as photo-Fenton catalyst probably due to a higher Al content. Even though optimization of all process parameters was not conducted in Oliveira et al (2011) research, $90 \%$ of indigo carmine dye decolourization was achieved with foundry waste sand as a heterogeneous catalyst. Similarly, the reaction was slower, with higher catalyst and oxidant concentration demand. Other reaction conditions were: $\mathrm{pH}=6,50 \mathrm{mg}$ dye/L and $210 \mathrm{~min}$. In the heterogeneous Fenton reaction, steel industry waste was efficient in azo dye removal $(20 \mathrm{mg} / \mathrm{L})$ with low catalyst loading and short reaction, but with high oxidant concentration $(34 \mathrm{mM})$. The advantage of using this waste catalyst is magnetic properties and easier removal from aqueous phase (Ali et al, 2013). Becelic-Tomin et al (2014) achieved complete decolourization of reactive, anthraquinone dye with pyrite ash as catalyst. Acidic Fenton conditions lead to high solubilisation of present heavy metals as $\mathrm{Pb}, \mathrm{Cu}$ and $\mathrm{Zn}$, where additional step after heterogeneous treatment for their removal was needed. Likewise, obtained removal of six dyes mixture $(702 \mathrm{mg} / \mathrm{L}$ ) was satisfactory, but $\mathrm{Pb}, \mathrm{Cu}, \mathrm{Cr}$ and $\mathrm{Cd}$ were leached from a pyrite cinder surface after real textile effluent treatment (Kerkez et al, 2018).

Besides solids without pre-treatment some waste materials should be modified prior Fenton reaction. Activated carbons produced from agricultural waste (biochars) are commonly impregnated with active ions (Fe). Rubeena et al (2018) prepared two biochars (rice husk and coir pith) and impregnated them with $\mathrm{Fe}\left(\mathrm{NO}_{3}\right)_{3}$ for Acid Red 1 dye $(50 \mathrm{mg} / \mathrm{L})$ decolourization. With impregnated rice husk biochar $98 \%$ removal was achieved at $\mathrm{pH} 3$ with $5 \mathrm{~g}$ catalyst/L and $16 \mathrm{mM} \mathrm{H}_{2} \mathrm{O}_{2}$. On the other hand, with coir pith biochar $99 \%$ degradation was obtained at $\mathrm{pH} 3$ with $4 \mathrm{~g}$ catalyst/L and $16 \mathrm{mM}$ oxidant. Both prepared materials showed high stability and activity in 4 successive cycles. Incipient wet impregnation was implemented for paper mill sludge modification (Zhou et al, 2015) to produce stable and active catalyst for Methylene Blue (50 mg/L) degradation. $94 \%$ dye removal was obtained at $\mathrm{pH} 4$ with $1 \mathrm{~g}$ catalyst/L and $2 \mathrm{ml} / \mathrm{L}$ of $3 \% \mathrm{H}_{2} \mathrm{O}_{2}$. Also, red mud (from aluminium production) can be further improved by controlled 
reduction with $\mathrm{H}_{2}$ to produce active Fe phases (Costa et al, 2010). They only gave insight in Methylene Blue $(100 \mathrm{mg} / \mathrm{L})$ decolourization (the optimization study was not carried out), where 65\% dye was removed at $\mathrm{pH}=6$ with $3 \mathrm{~g}$ red mud/ $\mathrm{L}$ and $300 \mathrm{mM} \mathrm{H}_{2} \mathrm{O}_{2}$.

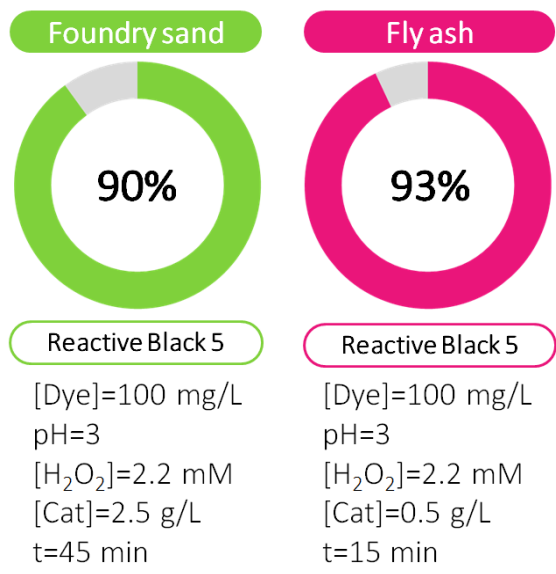

Rajput et al., 2016

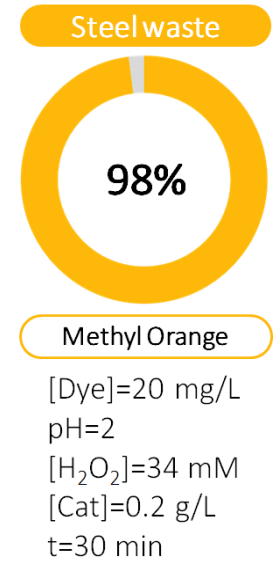

Ali et al., 2013

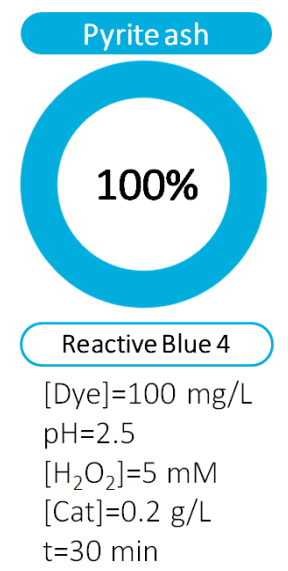

Becelic-Tomin et al., 2014

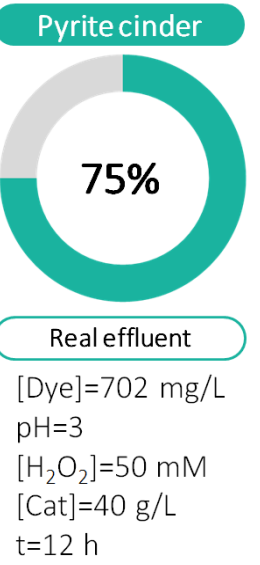

Kerkez et al., 2018

Figure 3: OFAT optimal conditions achieved with industrial waste catalysed Fenton process

Further, review of RSM based researches was conducted and selected papers are shown in Figure 4. Depicted results are obtained after CCD experiment design with various waste catalysts (coal burning bottom ash, lithium-ion batteries cathodes, sewage sludge, electric arc furnace dust and red mud). 91\% of chosen azo dye was degraded in photo-Fenton process catalysed with coal bottom ash (rich in $\mathrm{Al}_{2} \mathrm{O}_{3}$ and $\mathrm{SiO}_{2}$ ). This material is commonly disposed in abandoned mines or landfills with no commercial value (Drumm et al, 2019). Another catalyst was implemented in the de Matos Vargas et al (2019) work, which was produced from discarded mobile phone lithium-ion batteries. Namely, present cathodes are made from lithium cobalt oxide $\left(\mathrm{LiCOO}_{2}\right)$. After drying, solid residue was used in a heterogeneous Fenton process. Solution $\mathrm{pH}$ was not determined nor observed during treatment. When comparing it to other waste catalysts, high amount of oxidant $(1710 \mathrm{mM})$ was needed to decolorize low concentration of thiazine dye solution $(6 \mathrm{mg} / \mathrm{L}$ ). General residue of municipal wastewater treatment plant is sewage sludge abundant in Fe and Al after flocculation step in water purification (Grassi et al, 2020; Kong et al, 2016). Thermal treatment of Al-rich sludge was conducted in Grassi et al (2020) research, where mesoporous catalyst with $\mathrm{Al}_{2} \mathrm{O}_{3}$ and $\mathrm{Fe}_{2} \mathrm{O}_{3}$ active sites was formed. This material was used in fast $(30 \mathrm{~min})$ photo-Fenton treatment of azo dye (Amaranth) in acidic medium with low oxidant and catalyst demand. For comparison, Kong et al (2016) have treated Fe-rich sludge in carbothermal process in order to produce nano-flake catalyst for the heterogeneous Fenton reaction. Process optimization was conducted with OFAT methodology where $98 \%$ of Acid Orange II, azo dye, was removed after $30 \mathrm{~min}$ at $\mathrm{pH}=8$ with relatively higher Fenton reactants need $\left(2 \mathrm{~g}\right.$ catalyst/L and $17 \mathrm{mM} \mathrm{H}_{2} \mathrm{O}_{2}$ ). Also, investigation of Co impregnation of electric arc furnace dust and its use in the heterogeneous Fenton reaction was described in Maleki Rizi et al (2019). Complete decolourization of Methylene Blue was achieved with high catalyst load $(4 \mathrm{~g} / \mathrm{L})$ and low oxidant application $(0.5 \mathrm{mM})$. In contrast, 94\% of Methylene Blue was removed with $\mathrm{NaOH}$ activated electric arc furnace slag, used in photo-Fenton process (Nasuha et al, 2017). Optimal OFAT conditions were: $180 \mathrm{~min}, \mathrm{pH}=3,1 \mathrm{~g}$ catalyst/L and $20 \mathrm{mM} \mathrm{H}_{2} \mathrm{O}_{2}$. Real effluent from textile industry was decolorized with waste red mud (thermally treated) in Kulić et al (2018). Structure and concentration of present dyes were not indicated, but $80 \%$ heterogeneous Fenton process efficiency was achieved after 180 min with $1 \mathrm{~g} / \mathrm{L}$ of red mud in acidic medium. In Natarajan and Ponnaiah (2017) work red mud was used to extract $\mathrm{Fe}(\mathrm{II})$ oxalate and is further used to produce nanoparticles in reaction with black plum leaves extract. The nano-catalyst was used in BBD optimization of Reactive Blue 235 dye removal by Fenton process. $98 \%$ dye removal $\left(10 \mathrm{mg} / \mathrm{L}\right.$ ) was obtained with $1.5 \mathrm{~g}$ catalyst/L, $23 \% \mathrm{H}_{2} \mathrm{O}_{2}, 239$ min, while $\mathrm{pH}$ value was not indicated. Likewise, Kerkez et al (2017) prepared oak leaves nano zero valent Fe (nZVI) to treat three different dyes (Reactive Red 120, Reactive Blue 4 and Brilliant Blue R). Optimization of Fenton process parameters was conducted according to BBD. 99\% removal of reactive dyes (50 mg/L) was achieved with $0.4 \mathrm{~g} \mathrm{nZVI} / \mathrm{L}, \mathrm{pH}=2,9.9$ and $2.3 \mathrm{mM} \mathrm{H}_{2} \mathrm{O}_{2}$ for Reactive Red 120 and Reactive Blue 4 respectively. While $75 \%$ decolourization of Brilliant Blue $\mathrm{R}$ dye was obtained with same dye and catalyst concentration, $\mathrm{pH}$ value and with $10 \mathrm{mM} \mathrm{H}_{2} \mathrm{O}_{2}$. 


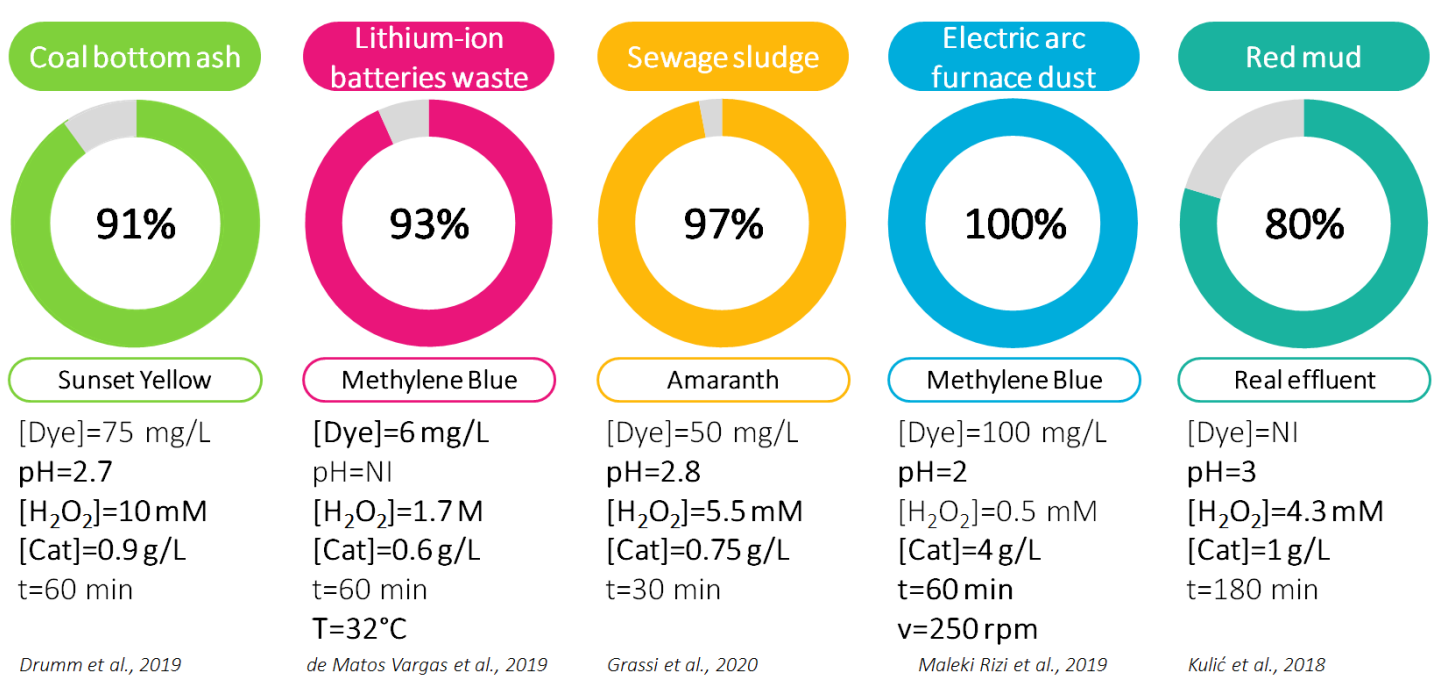

Figure 4: RSM optimal conditions achieved with industrial waste catalysed Fenton process; *NI-not indicated

\section{CONCLUSION}

The aim of this mini review is to give insight on the various waste materials use as Fenton reaction catalysts for dye removal. Published researches were selected based on applied optimization methods for evaluating main process parameters influence. It was revealed that catalyst concentration, oxidant concentration, $\mathrm{pH}$ value, dye concentration and reaction time are main factors that influence final decolourization efficiency. In this study fly ash, foundry sand, pyrite ash, steel industry waste, coal bottom ash, red mud, sewage sludge was covered as potential catalysts with thermal or without modification. While paper mill sludge, activated biochars and electric arc furnace dust were used after chemical modification in Fenton oxidation. Reported materials showed great potential from a decolourization efficiency point of view, thus reinforcing their value addition and possible future industrial symbiosis. But, in order to obtain fully sustainable waste management, further stability (leaching) studies of waste catalysts has to be done.

\section{ACKNOWLEDGEMENTS}

The authors acknowledge the financial support of the Science Fund of the Republic of Serbia for the Program for excellent projects of young researchers (PROMIS) - WasteWaterForce project (6066881) and the Ministry of Education, Science and Technological Development through the project No. 451-0368/2020-14/200156: "Innovative scientific and artistic research from the FTS (activity) domain".

\section{REFERENCES}

[1] Ali, M.-M., Gad-Allah, T.A., Badawy, M.I.: "Heterogeneous Fenton process using steel industry wastes for methyl orange degradation", Applied Water Science 3, 363-270, 2013. doi: 10.1007/s13201-013-0078-1.

[2] Becelic-Tomin, M., Dalmacija, B., Rajic, Lj., Tomasevic, D., Kerkez, Dj., Watson, M., Prica, M.: "Degradation of Anthraquinone Dye Reactive Blue 4 in Pyrite Ash Catalyzed Fenton Reaction", The Scientific World Journal 234654, 8, 2014. doi: 10.1155/2014/234654.

[3] Costa, R-C., Moura, F.-C., Oliveira, P.-F., Magalhães, F., Ardisson, J.D., Lago, R.M.: "Controlled reduction of red mud waste to produce active systems for environmental applications: Heterogeneous Fenton reaction and reduction of $\mathrm{Cr}(\mathrm{VI})^{\prime \prime}$, Chemosphere 78, 1116-1120, 2010. doi: 10.1016/j.chemosphere.2009.12.032.

[4] de Matos Vargas, A.M., da Silva Santos, C., Cagliari, J.V., Rossi, A.: "Multivariate optimization of the degradation conditions of methylene blue using a catalyst recovered from electronic waste", Journal of Environmental Chemical Engineering 7, 103191, 2019. doi: 10.1016/j.jece.2019.103191. 
[5] Drumm, F.C., Grassi, P., Sulkovski, A.A., Pfingsten Franco, D.S., Georgin, J., Dotto, G.L., Foletto, E.L., Jahn, S.L.: "Applicability of Coal Bottom Ash from Thermoelectric Power Plant as an Alternative Heterogeneous Catalyst in Photo-Fenton Reaction", Water, Air \& Soil Pollution 230, 274, 2019. doi: 10.1007/s11270-019-4327-2.

[6] Grassi, P., Drumm, F.C., Georgin, J., Pfingsten Franco, D.S., Foletto, E.L., Dotto, G.L., Jahn, S.L.: "Water treatment plant sludge as iron source to catalyze a heterogeneous photo-Fenton reaction", Environmental Technology \& Innovation 17, 100544, 2020. doi: 10.1016/j.eti.2019.100544.

[7] Karimifard, S., Moghaddam, M.-A.: "Application of response surface methodology in physicochemical removal of dyes from wastewater: A critical review", Science of the Total Environment 640-641, 772-797, 2018. doi: 10.1016/j.scitotenv.2018.05.355.

[8] Kerkez, Đ., Bečelić-Tomin, M., Kulić, A., Tomašević Pilipović, D., Leovac Maćerak, A., Dalmacija, B., Prica, M.: "Treatment of wastewater containing dye mixture using pyrite cinder in heterogeneous Fenton process", Proceedings of $9^{\text {th }}$ International Symposium on Graphic Engineering and Design 2018, (GRID: Novi Sad, SRB, 2018), pages 169-173.

[9] Kerkez, Dj., Becelic-Tomin, M., Tomasevic Pilipovic, D., Prica, M., Kulic, A., Dalmacija, B., Watson, M.: "Usage of green synthesized nZVI for degradation of three different dye molecules", Proceedings of $15^{\text {th }}$ International Conference on Environmental Science and Technology 2017, (CEST: Rhodes, GRE, 2017), pages 00983.

[10] Kong, L., Zhu, Y., Liu, M., Chang, X., Xiong, Y., Chen, D.: "Conversion of Fe-rich waste sludge into nano-flake Fe-SC hybrid Fenton-like catalyst for degradation of AOII", Environmental Pollution 216, 568-574, 2016. doi: 10.1016/j.envpol.2016.06.012.

[11] Kulić, A., Bečelić-Tomin, M., Kerkez, Đ., Pucar Milidrag, G., Kecić, V., Prica, M.: "Examination of the application possibilities of waste red mud in treatment of colored effluent", Proceedings of $9^{\text {th }}$ International Symposium on Graphic Engineering and Design 2018, (GRID: Novi Sad, Serbia, 2018), pages 175-180.

[12] Maleki Rizi, M.H., Alizadeh, M., Khanlarkhani, A., Martinez Huerta, M.V.: "The role of cobalt and copper nanoparticles on performance of magnetite-rich waste material in Fenton reaction", International Journal of Environmental Science and Technology 16, 373-382, 2019. doi: 10.1007/s13762-017-1579-5.

[13] Nasuha, N., Ismail, S., Hameed, B.H.: "Activated electric arc furnace slag as an effective and reusable Fenton-like catalyst for the photodegradation of methylene blue and acid blue 29", Journal of Environmental Management 196, 323-329, 2017. doi: 10.1016/j.jenvman.2017.02.070.

[14] Natarajan, E., Ponnaiah, G.P.: “Optimization of process parameters for the decolorization of Reactive Blue 235 dye by barium alginate immobilized iron nanoparticles synthesized from aluminum industry waste", Environmental Nanotechnology, Monitoring \& Management 7, 73-88, 2017. doi: 10.1016/j.enmm.2017.01.002.

[15] Oliveira, P.-F., Oliveira, L.D., Ardisson, J.D., Lago, R.M.: "Potential of modified iron-rich foundry waste for environmental applications: Fenton reaction and $\mathrm{Cr}(\mathrm{VI})$ reduction", Journal of Hazardous Materials 194, 393-398, 2011. doi: 10.1016/j.jhazmat.2011.08.002.

[16] Rajput, H., Verma, A., Kaur, M., Kaur, T., Toor, A.P.: “Heterogeneous solar photo-Fenton degradation of Reactive Black 5 using foundry sand and fly ash: value addition to waste", Journal of Environmental Engineering and Landscape Management 24(01), 124-132, 2016. doi: 10.3846/16486897.2015.1109517.

[17] Rubeena, K.K., Prasad Reddy, P.H., Laiju, A.R., Nidheesh, P.V.: "Iron impregnated biochars as heterogeneous Fenton catalyst for the degradation of acid red 1 dye", Journal of Environmental Management 226, 320-328, 2018. doi: 10.1016/j.jenvman.2018.08.055.

[18] Taelman, S.E., Tonini, D., Wandl, A., Dewulf, J.: “A Holistic Sustainability Framework for Waste Management in European Cities: Concept Develpoment", Sustainability 10, 2184, 2018. doi: 10.3390/su10072184.

[19] Zhou, G., Chen, Z., Fang, F., He, Y., Sun, H., Shi, H.: "Fenton-like degradation of Methylene Blue using paper mill sludge-derived magnetically separable heterogeneous catalyst: Characterization and mechanism", Journal of Environmental Sciences 35, 20-26, 2015. doi: 10.1016/j.jes.2015.01.026 


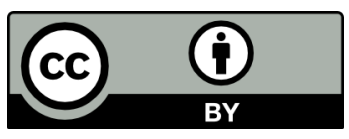

(C) 2020 Authors. Published by the University of Novi Sad, Faculty of Technical Sciences, Department of Graphic Engineering and Design. This article is an open access article distributed under the terms and conditions of the Creative Commons Attribution license 3.0 Serbia

(http://creativecommons.org/licenses/by/3.0/rs/). 